\title{
MEMBINCANG AYAT-AYAT MUHKAM DAN MUTASYABIH
}

\author{
Muhammad Anwar Firdausi \\ Fakultas Humaniora UIN Maulana Malik Ibrahim Malang \\ Email: dozya@yahoo.com
}

\section{Abstract}

Al Quran has become a guide for all Muslims in the world. Al Quran can not be compared with the books of the previous prophet sent by Allah. Therefore it becomes the most miracle, the greatest, and the most beautiful one of all time in the dynamics of human life. Even with its miracles, it becomes a cornerstone principle of life, a philosophy of life that is relevant and never unflagging despite having to constantly conflicting with the flow of evolving human thought. It can be proved by the increasing trust of men in every letter, word, sentence dangle with the logic of language, so that they are sure of the truth. Yet, in understanding the Quran, people especially Muslims still find it difficult to understand its meaning correctly, because there are passages that still require further clarification. In Islamic studies it is commonly referred to muhkam and mutashabihat verses. In understanding both many scholars argue, although the substance is equally true, they have dissimilar way only.

Al Quran telah menjadi pedoman bagi seluruh umat muslim di dunia. Al Quran tidak bisa diperbandingkan dengan kitab-kitab Nabi sebelumnya yang telah diturunkan oleh Allah. Oleh karena itu ia menjadi mukjizat terbesar, teragung, terindah sepanjang masa dalam dinamika kehidupan manusia. Bahkan dengan mukjizatnya, Al Quran menjadi landasan prinsip hidup, filosofi hidup yang relevan serta tak pernah kunjung padam meski harus senantiasa bergesekan dengan alur pikir manusia yang selalu berkembang. Hal itu bisa dibuktikan dengan semakin percaya manusia pada setiap huruf, lafad, kalimat yang teruntai dengan logika bahasa, sehingga yakin akan kebenarannya. Namun dalam memahami al Quran, manusia khususnya umat muslim masih menemukan kesulitan dalam memahami arti secara benar, sebab didalamnya terdapat ayat-ayat yang masih memerlukan penjelasan lebih lanjut. Dalam 
kajian studi Islam hal tersebut biasa disebut dengan ayat-ayat muhkam dan mutasyabihat. Dalam memahami kedua masalah tersebut para ulamapun banyak berselisih pendapat, meskipun pada subtansinya sama-sama benar, hanya caranya yang berbeda.

Keywords: muhkam, mutashabihat, miracle

\section{Pendahuluan}

Adalah al Quran Kitab Suci yang diturunkan Allah melalui Jibril kepada Nabi Muhammad SAW sebagai Kitab Suci yang terakhir dan suatu ringkasan dari Kitab-Kitab Suci yang pernah diturunkan Allah. Bahkan al Quran acapkali diseru oleh seluruh penganutnya untuk mengesahkan berbagai macam prilaku, memotivasi berbagai perjuangan, melandasi berbagai aspirasi, mensugesti dalam memenuhi segudang harapan dan memperteguh jati diri manusia yang meyakininya dalam menghadapi berbagai tantangan perkembangan zaman.

Bahkan bila dilihat pendapat Muhammad Abduh yang selaras dengan tendensi rasionalitasnya di bidang tafsir bahwa kemukjizatan al Quran menunjukkan adanya ketidakberdayaan zaman untuk menggugurkan apapun darinya. Ia juga menegaskan bahwa hanya al Quranlah satu-satunya kitab yang memuat berbagai masalah alam, secara empiris maupun sosial (Abdussalam, 1999: 132). Oleh karena itu al Quran adalah salah satu naskah atau risalah yang berjangkauan universal yang sering diperbincangkan dan didiskusikan, meski demikian kurang kita pahami secara keseluruhan. Mengingat penjelasan pesan-pesan Allah dan segala hikmahnya itu masih menjadi misteri bagi kebanyakan manusia. Sehingga kaum muslimin harus menakwilkannya dan harus mengeluarkan dari seluruh fenomenanya untuk disesuaikan dengan berbagai fenomena dan tradisi atau teori sains. Sehingga perkembangan ilmu pengetahuan manusia sesuai dengan realitasnya yang benar-benar riil dalam al Quran.

Misalkan dalam permasalahan muhkam dan mutasyabih yang terdapat dalam ayat-ayat al Quran. Bila umat Islam tidak memahami dengan baik dan benar keduanya, tentunya akan menimbulkan permasalahan yang mendasar dalam memahami al Quran. Untuk lebih jelasnya akan diuraikan secara terinci hal-hal yang berkaitan dengan kedua permasalahan tersebut di bawah ini. 


\section{Pengertian Muhkam dan Mutsyabih}

Muhkam berasal dari kata ihkam yang secara bahasa berarti kekukuhan, kesempurnaan, keseksamaan dan pencegahan. Akan tetapi semua pengertian tersebut kembali pada arti dasarnya yaitu pencegahan. Seperti pada kalimat ahkam al Amr yang berarti Dia menyempurnakan suatu hal dan mencegahnya dari kerusakan (Syadali, 1993: 199).

Sedangkan kata mutasyabih berasal dari kata tasyabuh secara etimologis berarti keserupaan dan kesamaan yang biasanya membawa kepada kesamaran antara dua hal (Syadali, 1993: 199). Seperti dalam ayat-ayat al Quran yang menggunakan kedua kata tersebut:

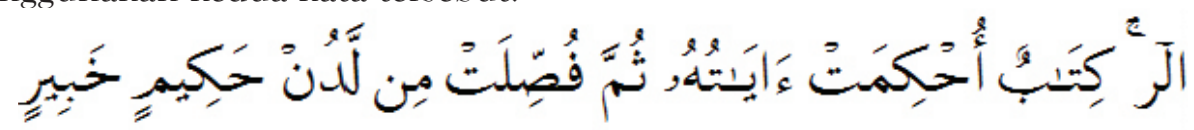

"Alif laam raa, (Inilah) suatu Kitab yang ayat-ayatNya disusun dengan rapi serta dijelaskan secara terperinci, yang diturunkan dari sisi (Allah) yang Maha Bijaksana lagi Maha tahu" (QS Hud: 1).

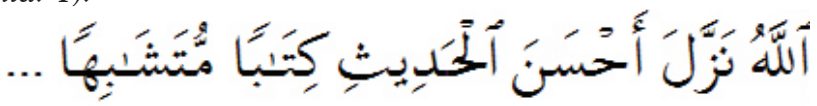

"Allah Telah menurunkan perkataan yang paling baik (yaitu) al Quran yang serupa (mutu ayat-ayatnya) lagi berulang-ulang...” (QS al Zumar: 23).

Kedua contoh ayat di atas terkesan menimbulkan pemahaman yang berbeda. Untuk itu, Ibnu Habib an Naisaburi berpendapat bahwa al Quran seluruhnya muhkam berdasarkan ayat pertama, dan al Quran seluruhnya adalah mutasyabih berdasarkan ayat kedua. Menurutnya ayat pertama adalah muhkamnya al Quran adalah kesempurnaannya dan tidak adanya pertentangan antara ayat-ayatnya. Sedangkan maksud mutasyabih pada ayat selanjutnya adalah menjelaskan segi kesamaan ayat-ayat al Quran dalam kebenaran kebaikan dan kemukjizatannya.

Pendapat itu juga sama seperti yang dilontarkan oleh M. Hasbi Ash Shiddieqy bahwa al Quran semuanya muhkamah, jika dimaksudkan dengan kemuhkamannya, dilihat dari komposisi lafadnya dan nilai estetika nadhamnya sungguh sangat sempurna. Ia juga mengatakan bahwa seluruh al Quran mutasyabih, jika dikehendaki kemutasyabihannya yaitu kemutamastilan serupa atau sebanding ayat-ayatnya baik dari aspek balaghohnya maupun i'jaznya (Hasbi, 1993: 166).

Oleh karena itu baik muhkam dan mutasyabih dengan memandang pengertian secara mutlak sebagaimana diatas tersebut tidak menafikan satu 
dengan yang lain, sehingga pernyataan al Quran itu seluruhnya muhkan adalah maksudnya itqon (kokoh, indah) artinya ayat-ayatnya serupa dan sebagiannya membenarkan sebagian yang lain.

Sedangkan pengertian muhkam dan mutsyabih secara terminologi, di kalangan ulama banyak berbeda pendapat. Seperti al Suyuti telah mengemukakan delapan belas definisi, dan al Zarkoni juga telah mengemukakan sebelas definisi pula. Dari seluruh definisi tersebut yang sering dipergunakan ialah sebagai berikut:

1. Muhkam adalah ayat yang mudah diketahui maksudnya, sedang mutasyabih hanyalah diketahui maksudnya oleh Allah sendiri.

2. Muhkam adalah ayat yang hanya mengandung satu wajah, sedang mutasyabih mengandung banyak wajah.

3. Muhkam adalah ayat yang maksudnya dapat deketahui secara langsung, tanpa memerlukan keterangan lain, sedang mutasyabih tidak demikian, ia memerlukan penjelasan dengan merujuk kepada ayat-ayat lain (al Qotton, 1994: 304).

4. Muhkam ialah ayat yang jelas ma'nanya dan tidak masuk kepadanya isykal (kepelikan). Mutasyabih ialah lawannya muhkam atas ismism musytarok dan lafalnya mubhamah (samar-samar) (Hasbi, 1993: 202).

Dari uraian diatas dapat diketahui dua hal penting yang perlu dicermati yaitu pertama, dalam memperbincangkan muhkam kita tidak banyak mengalami kesulitan yang berarti. Sedangkan kedua tentang mutasyabihah ternyata tidak sedikit menimbulkan masalah yang kiranya perlu dibahas lebih lanjut.

\section{Sikap Ulama dalam Menafsirkan Ayat-Ayat Mutasyabihah}

Ayat-ayat mutasyabihah timbul karena sifatnya yang mujmal (global) dan itu tentunya memerlukan takwil. Disisi lain sebagian besar ulama berpendapat, bahwa ayat-ayat mutasyabihah tidak diketahui takwilnya kecuali oleh Allah. Sementara orang-orang yang berilmu akan berhenti pada kalimat "dan orangorang yang berilmu mendalam", kalimat tersebut mengindikasikan para ulama ada yang mengetahui takwilnya.

Upaya mencari jalan tengah antara ulama yang berpendapat bahwa ayat mutasyabih tidak bisa ditakwilkan dengan ulama yang membolehkan takwil, oleh Raghib al Asfahani mengambil jalan tengah melalui pembagian ayat mutasyabih menjadi tiga bagian (al Saleh, 2002: 373). Pertama, lafadh atau 
ayat yang sama sekali tidak dapat diketahui hakekatnya. Seperti tentang waktu kiamat dan hal-hal ghaib lainnya seperti dalam Surat al An'am 59:

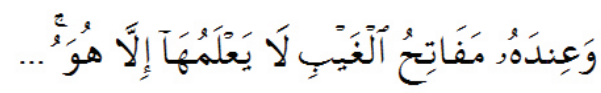

"Dan pada sisi Allahlah kunci-kunci semua yang ghaib tak ada yang mengetahuinya kecuali Dia sendiri...

Kedua, ayat-ayat yang setiap orang bisa mengetahui maksudnya melalui penelitian dan pengkajian. Seperti ayat-ayat mutasyabihat yang kesamarannya timbul akibat ringkas, panjang, urutan, dan seumpamanya. Seperti dalam firman Allah Surat an Nisa 3:

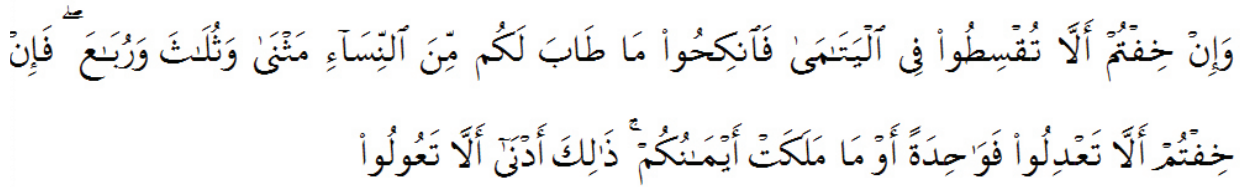

"Dan jika kamu takut tidak akan dapat berlaku adil terhadap (hak-hak) perempuan yang yatim (bilamana kamu mengawininya), Maka kawinilah wanita-wanita (lain) yang kamu senangi: dua, tiga atau empat. Kemudian jika kamu takut tidak akan dapat berlaku adil, Maka (kawinilah) seorang saja, atau budak-budak yang kamu miliki. yang demikian itu adalah lebih dekat kepada tidak berbuat aniaya"(QS an Nisa: 3).

Penjelasan berlaku adil ialah perlakuan yang adil dalam meladeni isteri seperti pakaian, tempat, giliran dan lain-lain yang bersifat lahiriyah. Islam memperbolehkan poligami dengan syarat-syarat tertentu. Sebelum turun ayat ini poligami sudah ada, dan pernah pula dijalankan oleh para nabi sebelum Nabi Muhammad SAW ayat ini membatasi poligami sampai empat orang saja.

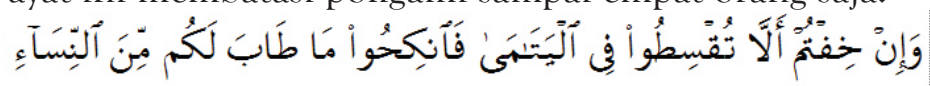

"Dan jika kamu takut tidak akan dapat berlaku adil terhadap (hak-hak) perempuan yang yatim, maka kawinilah wanita-wanita lain..." (QS An Nisa: 3).

Maksud ayat tersebut di atas tidak jelas, dan ditimbulkan akibat lafadnya yang ringkas. Karena kalimat asalnya berbunyi:

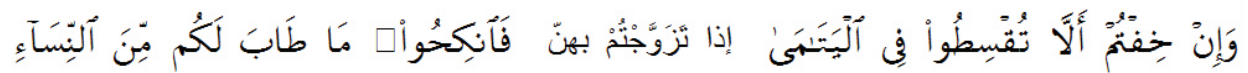

"Dan jika kamu takut tidak akan dapat berlaku adil terhadap perempuan yang yatim sekiranya kamu kawini mereka, maka kawinilah wanita-wanita selain mereka." 
Ketiga, ayat-ayat mutasyabihat yang maksudnya dapat diketahui oleh para ulama tertentu dan bukan semua ulama. Maksudnya yang demikian adalah makna-makna yang tinggi yang memenuhi hati orang-orang yang jernih jiwanya dan mujtahid.

Para ulama berbeda dalam menafsirkan ayat-ayat mutasyabihat. Sebagian mereka cenderung memahaminya secara leterlek (harfiah) dan sebagian yang lain melihatnya sebagai isyarat kepada takwil. Dalam hal ini sangat ditentukan oleh persepsi mereka dalam melihat ayat-ayat itu, apakah ia dapat ditafsirkan (ditakwilkan) atau tidak.

Dalam pandangan Subhi As Shalih, ia membedakan pendapat ulama dalam dua madzhab. Pertama, Madzhab Salaf, yaitu orang-orang yang mempercayai dan meyakini sifat-sifat mutasyabih dan menyerahkan hakekatnya kepada Allah sendiri (al Saleh, 1995: 211). Karena mereka menyerahkan urusan mengetahui hakekat maksud ayat-ayat mutasyabihat kepada Allah. Oleh karenanya, mereka disebut Mufawidah atau Tafwid. Sistem penafsiran tersebut secara umum digunakan Madzhab Salaf dalam memahami ayat-ayat mutasyabihah. Dalam aplikasinya mereka menggunakan argumen aqli dan naqli. Kedua, Madzhab Khalaf yaitu ulama yang menakwilkan lafal yang makna lahirnya mustahil dengan makna yang sesuai dan laik untuk dzat Allah. Oleh sebab itu mereka disebut Muawwilah atau Madzhab Takwil. Seperti mereka memaknakan istiwa dengan ketinggian yang abstrak, berupa pengendalian Allah terhadap alam. Kedatangan Allah diartikan dengan kedatangan perintahnya. Allah berada diatas hamba-Nya dengan Allah Maha Tinggi, bukan berada suatu tempat. Sisi Allah dengan hak Allah. Wajah dengan dzat mata dengan pengawasan, tangan dengan kekuasaan dan diri dengan siksa.

Di samping kedua madzhab diatas masih ada lagi madzhab ketiga seperti yang dikemukakan oleh as Suyuti bahwa Ibnu Daqiq berpendapat jika takwil itu dekat dari bahasa arab, maka tidak dipungkiri dan jika takwil itu jauh maka kita tawakkuf (tidak memutuskannya). Jadi kita meyakini maknanya menurut cara yang dimaksudkan serta mensucikan Tuhan dari sesuatu yang tidak laik bagi-Nya. Seperti sesuatu yang maknanya lafalnya nyata serta bisa dipahami dari percakapan orang arab kita terima yang demikian tanpa tawakkuf, contahnya:

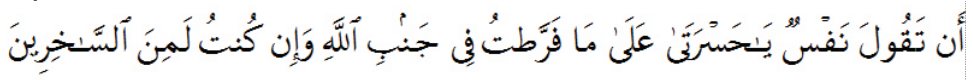

"Supaya jangan ada orang yang mengatakan: "Amat besar penyesalanku atas kelalaianku dalam (menunaikan kewajiban) terhadap Allah, sedang Aku Sesungguhnya termasuk orang-orang yang memperolok-olokkan (agama Allah)" (QS az Zumar: 56). 
Menurutnya sisi Allah diartikan dengan hak Allah.

Dari ketiga madzhab tersebut, masing-masing mempunyai argumentasi sendiri dan bisa dikompromikan. Sebab mereka percaya makna yang diambil dari hasil penakwilan dan penafsiran, bukanlah merupakan makna yang pasti bagi ayat-ayat mutasyabihat itu, dan tak seorang pun bisa menjamin bahwa itulah makna yang sebenarnya, dan mereka menyerahkan maknanya kepada Allah, sehingga pada akhirnya semua pihak bisa menerimanya.

\section{Huruf Al Muqotto'ah Dalam Pandangan Ulama}

Dalam pandangan as Suyuti huruf al muqotto'ah dikategorikan sebagai ayat-ayat mutasyabihat (Syadali dkk, 1997: 186). Oleh karena itu para ulama berbeda pandangan dalam menakwilkannya dan menafsirkannya sebagai berikut :

1. Az Zamaksyari dalam tafsirnya al Qasysyaf, bahwa huruf-huruf itu maknanya ada tiga yaitu merupakan nama surat, sumpah Allah dan agar menarik perhatian orang yang mendengarkannya.

2. Al Quwaibi mengatakan bahwasanya kalimat itu merupakan tanbih bagi Nabi. Maksudnya ketika Nabi dalam kondisi sibuk, Allah mengutus Jibril untuk memberikan perhatian terhadap apa yang disampaikan kepadanya.

3. As Sayyid Rasyid Ridha tidak membenarkan al Quwaibi, karena Nabi senantiasa dalam keadaan sadar dan senantiasa menanti kedatangan wahyu.

4. Ulama Salaf berpandangan bahwa fawatih as suwar atau huruf al muqotto'ah telah tersusun sejak zaman azali.

5. As Suyuti menukilkan pendapat Ibnu Abbas tentang huruf tersebut sebagai berikut (Syadali dkk, 1997: 196):

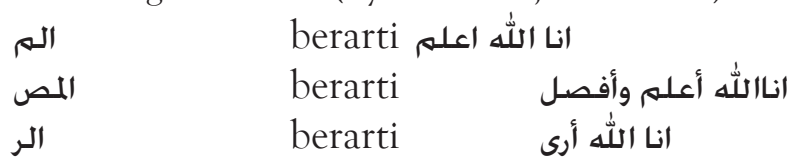

\section{Peranan Muhkam dan Mutasyabihat Dalam Penafsiran}

Dengan adanya ayat-ayat muhkam dan mutasyabihat itu sangatlah membantu dalam penafsiran ayat-ayat al Quran muhkam adalah perimbangan mutasyabih. Dan hal itu mendorong dan membantu para penafsir untuk mendefinisikannya secara tepat, sesuai dengan kandungan ayat-ayat tersebut. Ia juga berguna dalam penafsiran untuk mengetahui maksud Allah yang terdapat dalam ayat-ayat-Nya 
sesuai dengan kemampuannya, sehingga dalam penafsirannya bisa terungkap, baik dari aspek materinya, tujuannya, dan tingkat kebutuhan terhadapnya (al Farmawi, 2002: 7).

Ayat-ayat mutasyabihat yang banyak mengandung kemungkinan makna. Untuk itu para penafsir tidak boleh memahaminya secara berdiri sendiri. Untuk memahaminya secara benar harus melalui petunjuk ayat-ayat muhkamat. Oleh karena itu ayat-ayat mutasyabihat dapat dipahami dengan menunjuk kandungan ayat-ayat muhkamat.

\section{Hikmah Adanya Ayat-Ayat Mutasyabihat.}

Allah menciptakan segala sesuatu pasti ada hikmahnya, begitu juga dengan keberadaan ayat-ayat mutasyabihat memiliki hikmah sebagai berikut:

1. Sebagai rahmat Allah kepada manusia agar mereka selalu berpikir. Allah merahasiakan banyak hal, agar mereka mencari dan berupaya mendapatkan serta membuka misteri-misteri itu. Maka dengan adanya ayat-ayat mutasyabihat manusia tidak bergantung secara terus menerus pada penjelasan Allah, tetapi mereka bisa bergerak sendiri untuk mencari kebenaran dengan bantuan cahaya ayat-ayat Allah.

2. Sebagai cobaan dari Allah. Maksudnya dengan adanya ayat-ayat mutasyabihat, manusia diuji keimanannya, apakah mereka tetap percaya dan tunduk kepada ayat-ayat Allah atau berpaling dan cenderung memperalat ayat-ayat Allah untuk kepentingan pribadi (mengikuti hawa nafsu).

3. Sesuai dengan perkataan Fakhr ar Raziy, ayat-ayat al Quran ditujukan kepada semua manusia. Oleh karena itu ia diformulasikan dalam bahasa yang universal dan mengandung berbagai kemungkinan untuk ditakwilkan. Didalamnya mengandung berbagai isyarat dan ketentuan-ketentuan yang pasti. Dengan demikian ayat-ayat mutasyabihat adalah konsekuensi yang tidak dapat dielakkan untuk menjaga keutuhan dan universalitas al Quran itu sendiri.

4. Untuk menjadi bukti kelemahan manusia atas kebesaran Allah dan ketinggian ayat-ayat-Nya. Dengan adanya ayat-ayat mutasyabihat, manusia dijadikan tunduk terhadap ketentuan-Nya dan menghancurkan kesombongannya terhadap ketetapan-ketetapan Allah. Selanjutnya ayat-ayat mutasyabihat menunjukkan keterbatasan manusia yang harus mereka sadari setiap saat.

5. Untuk memberikan kebebasan kepada manusia untuk berbeda dalam 
penafsiran dalam rangka menjadikan mereka lebih terbuka dan toleran. Sekiranya semua ayat adalah muhkamat, maka yang terjadi adalah kebekuan dan statis, madzhab hanya satu, dan manusia tidak lagi berkompetisi dalam mencari kebenaran (Zarqony, 1998: 272).

\section{Simpulan}

Muhkam adalah ayat yang jelas atau rajih maknanya, sedangkan mutasyabihat ayat yang telah berdiri sendiri dan memerlukan keterangan tertentu. Mutasyabih adalah sebagai lawan dari kata muhkam yaitu ayat-ayat Al Quran yang mengandung kesamaran dan kepelikan dalam memahaminya. Allah menurunkan ayat-ayat mutasyabihat untuk menunjukkan kebesarannya, dan menunjukkan kepada manusia untuk berpikir dan mengungkap rahasianya. Karena kesamarannya, para ulama berbeda dalam mendifinisikannya secara tepat. Namun mereka mengakui bahwa ayat mutasyabih tersebut eksis dalam al Quran. Mereka juga berbeda pendapat dalam memberikan justifikasi apakah ayat-ayat mutasyabih tersebut dapat ditakwilkan atau dipahami maknanya oleh manusia atau tidak.

\section{Daftar Pustaka}

Abdussalam, Abdul Majid. 1997. Visi dan Paradigma Tafsir Al Quran Kontemporer. Bangil: al Izzah

Al Qotton, Manna Khalil. 1994. Studi Ilmu-Ilmu Al Quran. Bogor: Litera Antar Nusa.

Al Saleh, Subhi. 1995. Membahas Ilmu-Ilmu Al Quran. Jakarta: Pustaka Firdaus.

Al Farmawi, Abd.Hayy. 2002. Metode Tafsir Maudhu'iy. Jakarta: PT. Raja Grafindo Persada.

Ash Shiddieqy, M. Hasbi. 1993. Ilmu-Ilmu Al Quran. Jakarta: Bulan Bintang.

Al Zarqony. 1998. Manahil al Irfan fi Ulumil al Quran. Beirut Lebanon: Darul Kitab al Arobi.

Syadali, Ahmad dan Rofi'I, Ahmad. 1997. Ulumul Quran I. Bandung: CV.Pustaka Setia. 